\title{
Percorrendo o labirinto com Marcel Duchamp ${ }^{1}$
}

\author{
Flávia Dutra Cordeiro²
}

\begin{abstract}
Resumo
Demonstrar como as obras do artista Marcel Duchamp se inserem na Arte Contemporânea e como a existência de vários dos seus fragmentos, esboços e estudos são pontos centrais para a construção de mundos de devaneios que trazem conceitos intercalados de forma labiríntica. Os estudos e obras de Duchamp são parte integrante de um labirinto que percorre o espaço-tempo e cujas marcas estão fortemente associadas ao modo de se pensar a Arte Contemporânea quando inclui o outro. O que perpassa pela abrangência do outro como co-artista carrega em si algo de subjetivo, o que tornou possível aproximarem-se várias correntes de pensamento, fazendo com que eles se encontrassem através desta pesquisa cujos conceitos foram sendo delineados durante a sua realização. Analisar e pesquisar faz parte do processo desenvolvido e traz consigo a proximidade entre as obras de Duchamp e o que tenho feito durante alguns anos através da Arte.
\end{abstract}

Palavras-chave: Arte Contemporânea. Marcel Duchamp. Labirinto. Androgenia.

\begin{abstract}
To show how the works of the artist Marcel Duchamp insert in Contemporary Art and how the existence of its several fragments, sketches and studies are central points for the construction of a world of reveries that brings separate concepts in a labyrinthine way. The studies and works of Duchamp are parts of a maze that runs through time-space and whose marks are strongly associated to the way of thinking the Contemporany Art when it includes the other. What passes through the span of the other as co-artist carries in itself something subjective, what made possible to approach several chains of thing, making possible for then to find themselves through this research whose concepts were outline during its accomplishment. To analyse and research are part of the developed process and bring the aprroach between the works of Duchamp and whats I have done during some years throug the Art.
\end{abstract}

\footnotetext{
${ }^{1}$ Conceitos da Dissertação de Mestrado realizada na UFMG onde se encontra presente a relação sobre as obras do artista francês Marcel Duchamp associadas ao modelo contemporâneo de labirinto.

${ }^{2}$ Artista Multimídia, Professora e Mestre em Arte e Tecnologia da Imagem pela UFMG onde teve como orientadora a profa. Dra. Maria do Carmo de Freitas Veneroso.
} 


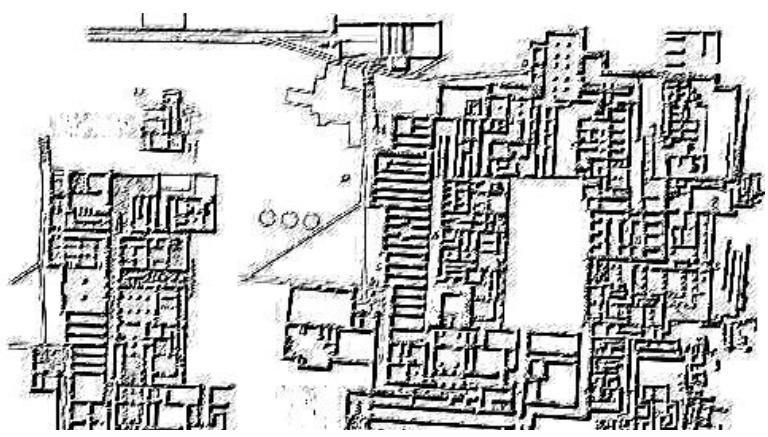

Figura 01. - Planta baixa do palácio do rei Minos, Creta.

Cerca de 1600 a.C

Labirinto é, essencialmente, um entrecruzamento de caminhos, dos quais alguns não têm saída e constituem, assim, impasses; no meio deles é mister descobrir a rota que conduz ao centro dessa bizarra teia de aranha. A comparação com a teia de aranha não é, aliás, exata, porque a teia é simétrica e regular, enquanto a essência mesma do labirinto é circunscrever no menor espaço possível o mais completo emaranhamento de veredas e retardar, assim, a chegada do viajante ao centro que deseja atingir (DA VINCI apud CHEVALIER, 1982, p. 530). 
Os traçados, as formas e as simbologias do labirinto são empregados de diferentes modos desde a Antiguidade. Pode-se encontrá-lo no percurso de algumas grutas préhistóricas; desenhado, segundo Virgílio, sobre a porta da caverna da sibila de Cumas; nas danças e rituais mágicos dos índios americanos; no Egito e em diversas regiões que vão da Grécia à China. Pode-se vê-lo, também, na relação comercial dos gregos que cunharam moedas com a imagem do labirinto (FIG. 2).

Os gregos mantinham com a mitologia uma relação em que o mito fazia parte da própria vida. Segundo a mitologia grega, Dédalo foi quem projetou e criou o labirinto a partir da planta baixa do palácio do rei Minos. Havia um intuito inicial de se mostrar esse local como um lugar sem saída, um encontro com a morte - o Minotauro. É interessante perceber que, apesar dessa intenção, sempre houve saídas, seja através do fio que Ariadne deu a Teseu, da construção de asas que Dédalo fez para si e para seu filho Ícaro (FIG. 3) ou outras que poderiam ser projetadas para se compreender esse local e a forma de desmembrá-lo como acontece no processo artístico que se

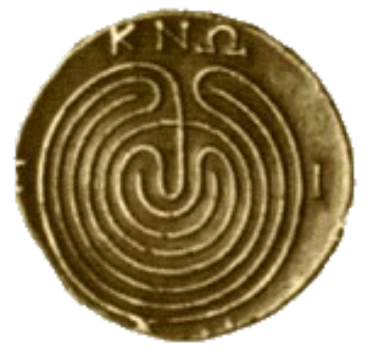

Figura 2- O mítico labirinto cunhado em uma moeda.

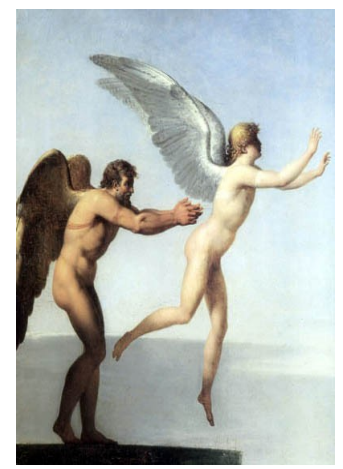

Figura 3-

Dédalo e İcaro.

Fonte: Charles- Paul Landon, 1799

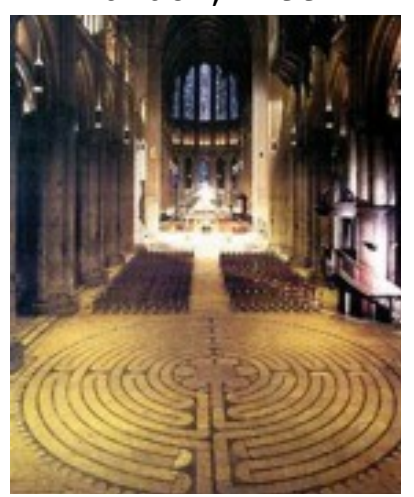

FIGURA 4 - França, Labirinto na Nave da Catedral de Chartres. 
deseja exemplificar durante a obra do artista francês Marcel Duchamp.

Na Idade Média, o labirinto vai ser empregado como um meio de se levantar a discussão sobre o lugar do homem e a sua fragilidade em relação a Deus. Isso através das grandes dimensões que os labirintos construídos dentro das catedrais mantinham em relação ao homem. Em algumas igrejas, era possível ver, sobre os solos, os labirintos que serviam como territórios para demarcar-se ou colocar a assinatura de confrarias iniciatórias onde $\mathrm{o}$ arquiteto posiciona $\mathrm{o}$ centro de acordo com a ordem. Assim, o centro continha algo de iniciatório para o aspirante que desejava estar ligado aos segredos de uma viagem que poderia ser feita de forma territorial ou através de meios psíquicos para chegar ao centro de si mesmo.

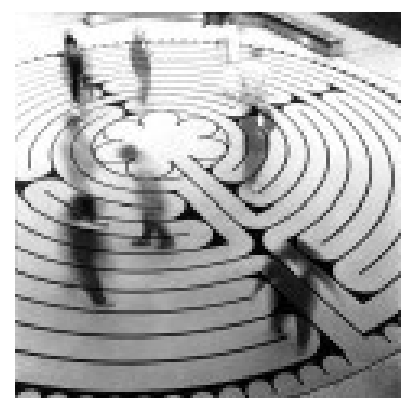

FIGURA 5 - Labirinto baseado na Catedral de Chartres, EUA.

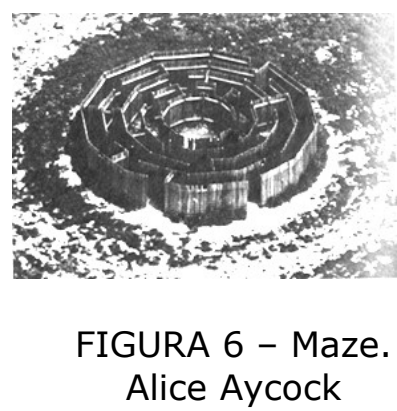

Aos poucos, o homem foi se transformando e, com ele, a Arquitetura foi acompanhando suas aspirações, mas o labirinto continuou a habitar o consciente e o inconsciente humanos como um espaço de passagem e transformação não só espiritual, mas também urbana. O labirinto na nave da Catedral de Chartres, na França (FIG. 4), serviu de modelo para uma Igreja americana (FIG. 5) cujo intuito é ser um espaço de deslocamento, movimentação, passagem e meditação.

Hoje se depara com o labirinto como uma situação da pós-modernidade, em que o que há são diversos caminhos que não possuem só um centro, mas são espaços de deslocamentos que possibilitam movimentos diversos. A entrada do labirinto tornou-se, 
ao mesmo tempo, a própria saída, capaz de transpor e transportar as pessoas, dependendo do ponto onde cada uma se encontre.

Pode-se ir, vir, sair, entrar ou se manter no labirinto que se constrói, reconstrói ou se destrói a partir de cada passo dado. Alguns artistas pós-modernos continuaram a construir labirintos baseados em construções hipotéticas, cidades imaginárias e projeções da própria mente através das relações que foram adquirindo em relação ao espaço. No final da década de 60 e início da de 70, labirintos foram desenvolvidos em diferentes escalas e com intenções variadas (FIG.6, 7, 8, 9). Alguns em pequenos formatos e para serem vistos em galerias e museus. Outros foram feitos em espaços externos onde os trabalhos começaram a adquirir inter-relação com a própria arquitetura através de interferências no meio ambiente. Richard Fleischner participou desse movimento conhecido como Land $\mathrm{Art}^{3}$, com um labirinto no gelo (FIG.10).

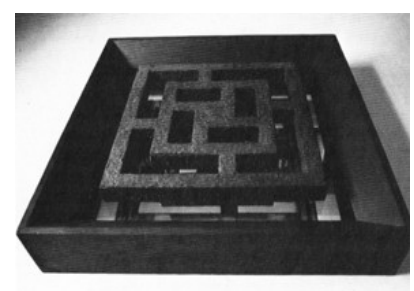

FIGURA 7 - Labyrinth.

Patrick Ireland, 1967.

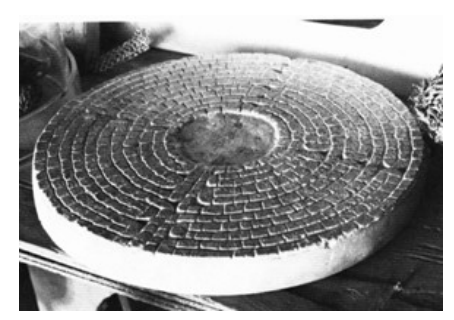

FIGURA 8 - Plaster labyrinth.

Terry Fox, 1972.

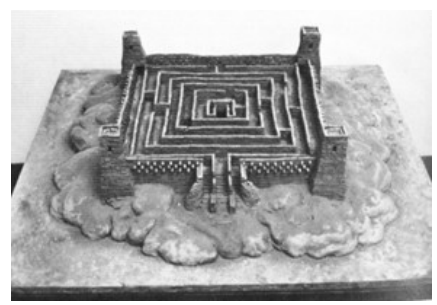

FIGURA 9 - Labyrinth.

Charles Simonds, 1973.

\footnotetext{
${ }^{3}$ Land Art: Movimento realizado principalmente nos Estados Unidos tendo como base a natureza.
} 


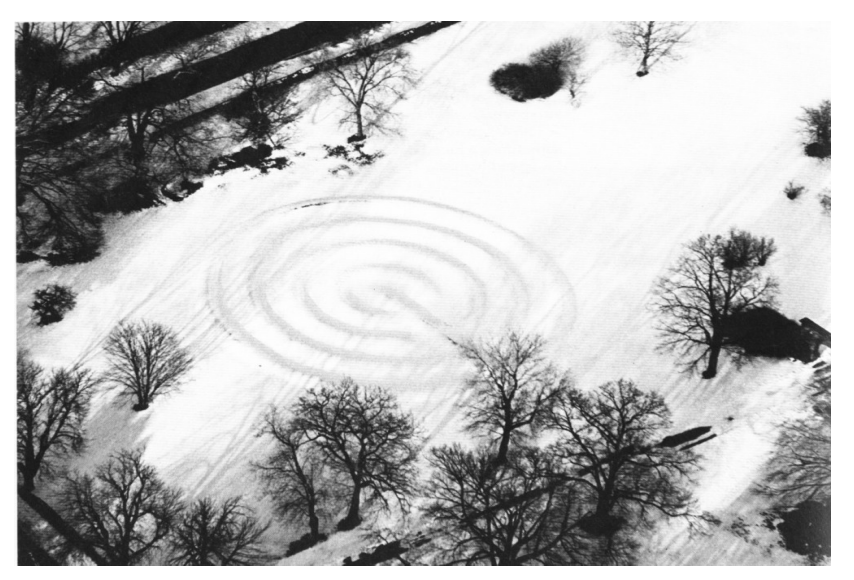

FIGURA 10 - Sod Moze.

Richard Fleischner , 1974.

O labirinto continua, pois, a sua rede, agora mais precisamente se engendrando pelo mundo contemporâneo das novas tecnologias, no qual as cidades são identificadas com as redes da internet e cujos locais confusos e cheios de tramas levam a fendas pelas quais é possível perceber saídas. Mesmo que algumas das associações do labirinto estejam ligadas à confusão, tende-se para uma tentativa de exploração desse local, onde "nunca haverá uma porta. Estás cá dentro e a fortaleza abarca o universo e não possui anverso nem reverso..." (BORGES, 1998, p. 366).

Esse universo de que fala Borges possui diversos labirintos e a relação pode ser construida junto a arte que através dos tempos foi sendo formada como consciência da história atemporal e nos legou um conjunto de obras cujo questionamento muitas vezes representa uma ligação entre o tempo-espaço e o labirinto presente nas obras do artista Marcel Duchamp. 


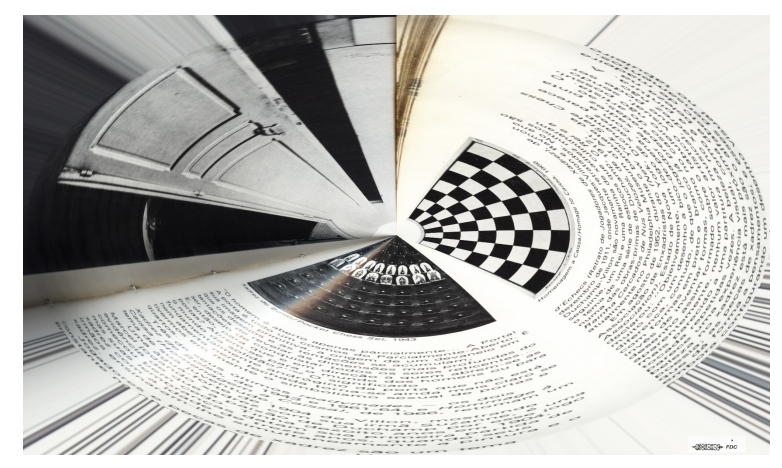

FIGURA 11 - Livro aberto pelas coordenadas polares.

Flávia Dutra, 2004.

Perceber o labirinto como uma metáfora da porta-fenda-cidade-caminho faz parte da necessidade de se trilhar um percurso que conserva a peculiaridade de seu interior incerto. Metaforicamente, pode-se abordar as obras, escritos e esboços de Marcel Duchamp, como o "fio de Ariadne" para a Arte Contemporânea, através de um labirinto que se comporta como um lugar de passagem.

Duchamp construiu um labirinto a partir de suas idéias e estas foram adquirindo desdobramentos, como um livro circular (FIG. 11). Essas idéias continuam em constante trânsito pelos territórios permeáveis de uma cidade em extensão, cuja entrada pode ser o local da ambigüidade e do estranhamento que ocorre quando nos deparamos com uma porta (FIG. 12) que Duchamp construiu no seu estúdio em 1927 e que traz em si uma complexidade de sentidos. Essa porta ficava ao mesmo tempo aberta e fechada, servindo de passagem entre dois cômodos e às vezes ficava no meio, partindo ou desconstruindo a função social que Ihe foi determinada, ou seja, a de um objeto utilitário. Ela traz o hibridismo ao ser e não ser um objeto de uso. Reutilizando essa imagem (FIG. 13), a porta foi invertida, não estando fixa em qualquer dos seus pontos, mas como uma continuidade do espaço. Ou seja, ela não está apoiada, mas continua subindo, invertendo e transformando o modo de perceberem-se as construções dos objetos no espaço. Isso só pode existir de maneira virtual, pois a porta está suspensa no ar. 
Em "Fechadura de Segurança com Colher" (FIG. 14), Duchamp já se colocava frente a frente com o olhar de quem quer penetrar o que está do outro lado, ou seja, havia um intuito de provocar o voyeurismo, como alguém que não quer mostrar, mas deixa a porta entreaberta ou cria uma pequena fresta, como a de "Dados: $1 .{ }^{\circ} \mathrm{A}$ queda de água, $2 .{ }^{\circ} \mathrm{O}$ gás de iluminação " (FIG. 15). A imagem traz uma porta externa, que contém por trás um outro universo que Duchamp ocultou por 20 anos como se quisesse preservar os seus segredos e intimidades.

O homem é aberto apenas parcialmente... A Porta! A porta é todo o cosmos do parcialmente-aberto. É sua imagem primitiva a origem de um devaneio em que os desejos e as tentações se acumulam, tentações de revelar as dimensões mais profundas do ser, desejo de conquistar todos os seres reticentes... E, então, para que e em direção a quem se abrem as portas? Abre-se para o mundo dos homens ou para o mundo da solidão? (BACHELARD, 1961, p. 200-1).
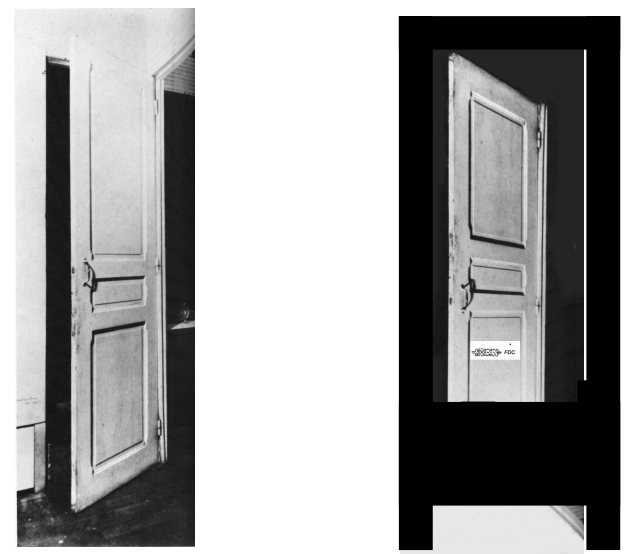

FIGURA 13 - Em suspenso.

Flávia Dutra, 2004.

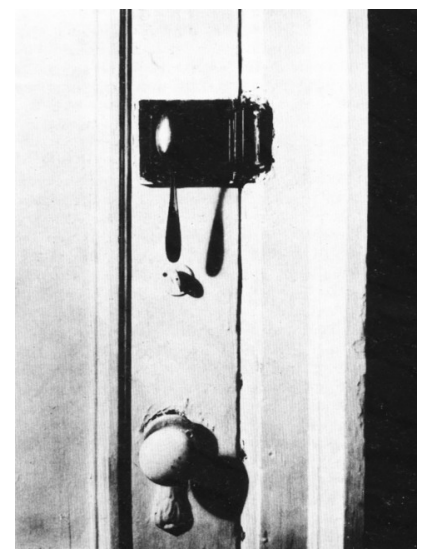

FIGURA 14 - Fechadura de segurança com colher.

Duchamp, 1957.

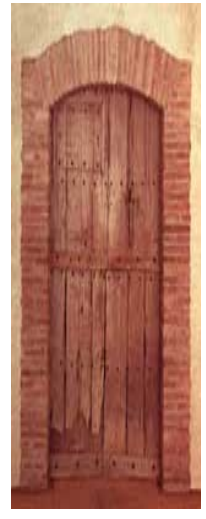

FIGURA 15 Dados: 1.0 A Queda de Água, 2.0 O Gás de Iluminação.

Duchamp, 1946-66. 
As portas deixam, através de suas fendas, que as passagens sejam construídas de acordo com o espaço-tempo a ser formado a partir das cidades. Olgária Matos, comentando o vídeo "Paisagens Urbanas", de Nelson Brissac Peixoto, desenvolveu uma distinção existente entre a cidade "superficial, racionalista, aquela em que triunfa a linha reta, onde o caminho que tomamos para chegar a uma determinada finalidade é o caminho da rotina, da repetição e do mesmo" (MATOS, 2003) Mudando o itinerário, propôs, em contrapartida: "uma outra abordagem da mesma cidade, que não é a abordagem da cidade superficial, mas é aquela cidade subterrânea, a cidade da memória e é a cidade labiríntica" (MATOS, 2003).

Torna-se importante citar a existência de uma outra cidade, que é percebida como sendo aquela que abarca as diferenças e que pode ser considerada uma cidade "rizomática". Deleuze e Guattari empregaram o conceito de rizoma para descrever os acontecimentos num espaço e tempo não fixos, capazes de se deslocar no meio em que a superfície atua, onde "qualquer ponto de um rizoma pode ser conectado a qualquer outro e deve sê-lo. É muito diferente da árvore ou da raiz que fixa um ponto, uma ordem" (DELEUZE; GUATARRI, p. 15, 1995) .

A cidade superficial atua como esse lugar no qual a linguagem se abre nos espaços vazios e multiplicadores, onde é viável ao pensamento se inserir na arquitetura do labirinto, "onde o sentido retorna para o lugar do qual veio, isto é, desaparece em sua própria impotência. Mas seu desaparecimento é o que aparece, abrindo, portanto, a mente para a virtualidade" (COSTA, 2004). Essa virtualidade se faz através de movimentos cíclicos nos quais se encontra um movimento de ir e vir no instante frágil dos sucessivos agora que trazem a arte para o campo virtual.

Essa se desenvolve a partir dos elos e cadeias que cada um vai compondo dentro dessa cidade que traz a situação do espaço e do tempo, relacionando-os com o labirinto a partir 
de uma concepção que muito se assemelha à do modelo da Internacional "situationniste"4, pois se constrói um território que abriga uma "extensão geográfica, sem centro ou periferia, chamada metrópole, capaz de fornecer à arquitetura seu material não mais forma que comove, mas situações que impressionam e movem o habitante" (VELLOSO, 2002, p. 17).

A cidade "rizomática" é em si a cidade das memórias labirínticas de Borges a Olgária e se permuta com a cidade situacionista, interpretada por Constant como a "Nova Babilônia", um "labirinto imensurável" (FIG. 16), cheio de escadas. Nele se pode perder o domínio, pois não há necessidade nem condições de controlar ou prever as atitudes e a maneira de cada um se posicionar, integrar e interagir com o espaço-tempo, uma vez que o andarilho ou aquele que está de passagem não se mantém numa posição fixa e definida para se deslocar no espaço, pois cada um se posiciona a seu modo. Pode-se pensar o conceito do ser-espaço-tempo através de uma cidade

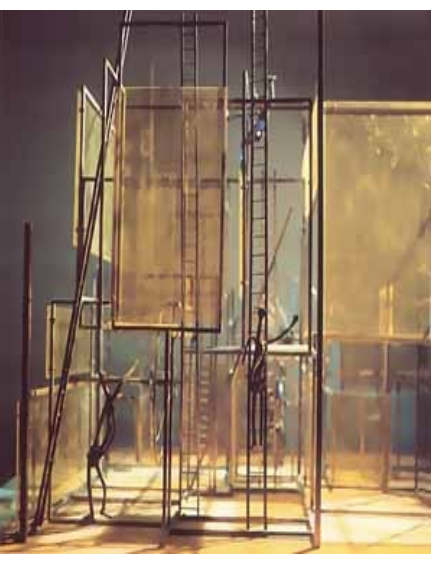

FIGURA 16 - Labirinto de escadas.

Constant, 1967. "aposicional", que abarca a diversidade e as diferenças e onde também cabem inúmeras cidades imaginárias onde a arte se desloca.

Essa cidade "rizomática" e "aposicional" faz parte das cidades invisíveis de Ítalo Calvino, sobre as quais Marco Pólo, o viajante, o nômade, comenta de forma inaugural as trilhas percorridas a partir de um modelo de cidade que se desmembra. Marco Pólo responde ao imperador Khan o modelo de cidade de onde ele extrai todas as outras:

\footnotetext{
${ }^{4}$ A Internacional Situacionniste foi um movimento que reivindicava mudanças no meio arquitetônico. Explorando o espaço e o tempo de formas interrelacionadas.
} 
- É uma cidade feita só de exceções, impedimentos, contradições, incongruências, contra-sensos. Se uma cidade assim é o que há de mais improvável, diminuindo-se o número dos elementos anormais aumenta a probabilidade de que a cidade realmente exista (CALVINO, 1990, p. 67).

Por ser permeável, essa cidade é também acontecimento dos invisíveis que têm atravessado a obra de Marcel Duchamp. Ela suscita uma busca pelos vestígios que permitem um levantamento de dados no tempo-espaço, cujo mecanismo de uma percepção textual-visual entrelaçada faz emergir parte de uma obra em constante processo de ramificação como labirinto real e virtual.

Isso ocorre na mente e na visão dos acontecimentos cujos movimentos centrífugo e centrípeto relaciona-se com a estratégia cognitiva sobre o olhar distanciado que permite um afastamento do visível, e o olhar aproximado que faz sentir o indeterminado.

Por olhar distanciado, pode-se entender aquilo que está além do meramente visível, quando Duchamp se pôs à margem da pintura apenas com o caráter retiniano. Por olhar aproximado, entende-se o indeterminado, que contém a visualidade que vai além da mera retina e leva à constituição do próprio olhar que vai ao cérebro para a formação da imagem e faz uso do intelecto para a compreensão e percepção do que se apresenta à mente no campo empírico e cognitivo, estabelecendo não o ponto de visão, mas a superfície como um todo labirintico.

É na formação, transformação e desconstrução labiríntica da linguagem plástica-verbal que se pode perceber a arte de Marcel Duchamp como um todo fragmentado na sua própria singularidade universal ao perceber a linguagem como consciência em estado de latência. Para Wittgenstein, em suas investigações: "nossa linguagem descreve, primeiramente, uma imagem. O que deve acontecer com a imagem, como deve ser empregada, permanece obscuro" (WITTGENSTEIN, 1994, p. 244). 
Esse lugar ou estado obscuro é a tomada de consciência da importância de um questionamento sobre a visão e a sua formação no cérebro como labirinto. Isso ocorre principalmente quando Duchamp sugere o pensamento circulando através da idéiaobjeto, metamorfoseando-a num "permutatório" de palavras-objeto mediante um jogo que se dá tanto na mente como aleatoriamente, através do acaso que explode as palavras e o objeto em si. Nesse jogo, é o próprio significado que se desloca no "nãolugar", no invisível do significante, sendo que se pode considerar o significado como o lugar de passagem do signo ao significante e vice-versa. Isso dá uma pluralidade decorrente da concepção de significado para Duchamp, quando ele afirma que "há uma espécie de explosão no significado de certas palavras: elas têm mais valor do que seu significado no dicionário" (CABANNE, 2001, p. 24).

Existe uma extensão do significado no mundo das interpretações que vai além do dicionário, por alargá-lo, deixando perceber que junto ao mesmo pode haver uma relação com os significantes. Ao perceber a fragilidade de um proferimento e sua validez, chegase às dimensões do que Habermas propõe a partir do momento em que "a linguagem pode tornar-se autônoma (no lugar da subjetividade), assumindo forma de destino epocal do ser, do delírio dos significantes..." (HABERMAS, 1990, p. 237). Essa autonomia se dá quando a linguagem retorna para o lugar que se torna o meio pelo qual o sentido tenta capturar o que se instala como área de reserva, pois a linguagem persiste e subsiste na ausência da coisa ficando no local labirintico.

Duchamp já se antecipara aos princípios desse pensamento, principalmente quando quebra as estruturas gramaticais e as suas regras geradoras, em que o labirinto é assumido como um jogo de linguagem. É claro que os movimentos surrealista e dadaísta muito contribuíram para isso, mas Duchamp criou seu próprio sistema, um modo particular de se pensar e desestruturar as normas e formas da arte, que vigoraram até o início do séc.XX. Começa, então, um questionamento sobre a crítica de arte e sobre o 
discurso, o que levou Duchamp a uma atitude da qual ele "tira da obra de arte, de uma certa maneira, tudo o que é supérfluo, atendo-se ao conceito, ao significado" (VENEROSO, 2000, p. 173).

Duchamp fez interrogações sobre o significado da arte e provocou, com isso, uma abertura que leva ao pensamento contemporâneo e pós-estruturalista, em que o sentido traz para uma situação que:

[...] complica-se pelo fato de que o sentido existe somente na relação entre significantes. Desse modo, não pode nunca ser definido com exatidão, como quando um significante estava preso a um significado. No pós-estruturalismo, o sentido está constantemente sendo adiado. Sempre escapará algo na tentativa de uma declaração clara e definitiva. Conseqüentemente, a linguagem é assediada pelo que não é ou não pode ser dito (HEARTNEY, 2002, p. 9).

Muito se tem falado do silêncio de Duchamp; um silêncio que fala e incomodou-incomoda a muitos (FIG. 17), pois em suas obras está inserido o que não pode ser dito e visto obviamente. Talvez ninguém tenha falado mais e de uma forma tão pessoal quanto ele com o seu "silêncio". Principalmente quando construiu uma genealogia do pensamento baseada em trocadilhos, na fonética das palavras, na percepção da perda de palavras que caem de um anúncio e cuja percepção em relação às coisas do cotidiano, questionamentos sobre a vida das palavras e dos objetos. Tanto os títulos como os objetos escolhidos por Duchamp demonstram a relação intrínseca e consciente da importância dada à abertura das palavras.

É nessa abertura que se encontram questionamentos vindos de um labirinto formador de palavras.

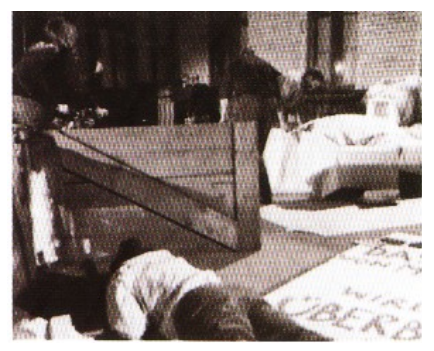


FIGURA 17 - Clichê do "happening": o silêncio de Marcel Duchamp é sobrestimado. Dusseldorf, Estúdio de TV, 1964.

Joseph Beuys, 1964.

Ao desenvolver "Com um Barulho Secreto", cujo esboço pode ser visto na FIG. 18, Duchamp deixou que a abertura das palavras e dos seus significados se ampliassem através da possibilidade de interferências internas e externas que poderiam ser feitas nesse "ready-made aidé", ou seja, "ready-made" ajudado: "Fazer um 'ready-made`com uma caixa, colocando algo dentro, que seja irreconhecível pelo som e soldar a caixa" (DUCHAMP, 1978, p. 42).

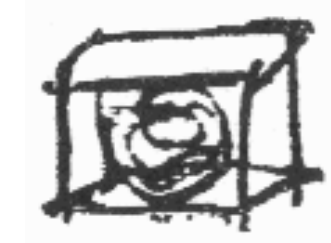

FIGURA 18 - Esboço de Com Barulho Secreto.Marcel Duchamp

Na chapa superior do objeto há um jogo de palavras a ser preenchido: 


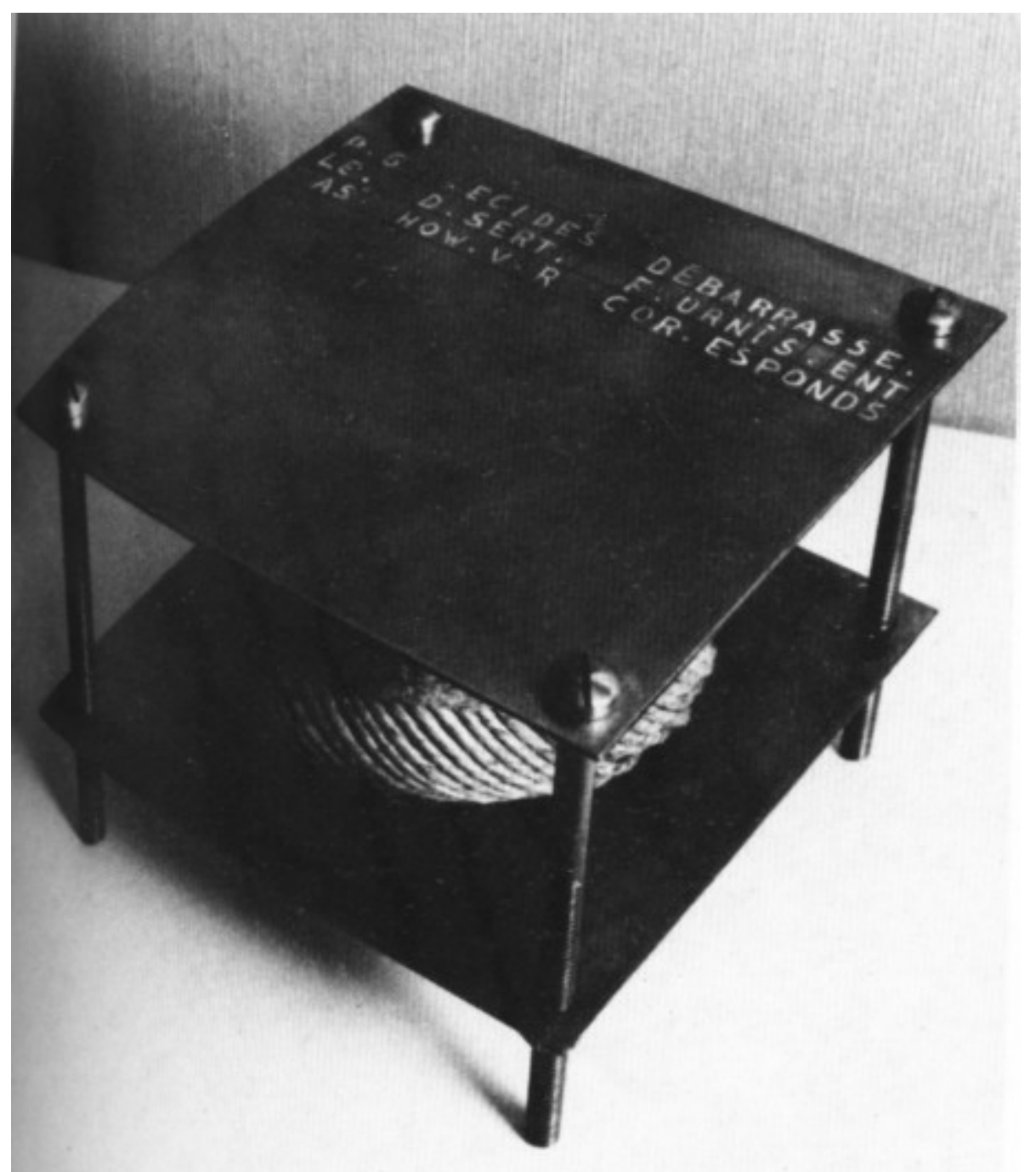

FIGURA 19 - Com um barulho secreto/"with hidden noise".

Marcel Duchamp, 1916, réplica de 1964.

\begin{tabular}{|l|}
\hline P.G. ÉCIDES DÉBARASSÉ \\
\hline LE. D.SERT. F.URNIS. ENT \\
\hline AS HOW.V.R. COR.ESPONDS \\
\hline
\end{tabular}


Esse vazio que ocorre perante a supressão de algumas letras deixa que o Inglês e o Francês sejam percebidos de forma complementar, pois algumas letras da primeira linha devem ser repetidas na segunda linha e algumas da segunda na terceira linha. Isto propõe uma fragmentação e um deslocamento da leitura, que pode ser feita na horizontal, na vertical ou por partes, deixando em suspenso o próprio significado, pois as palavras permanecem de forma labirintica e passíveis de serem construídas e lidas de maneiras diversas. Essa é apenas uma das partes instigantes desse "ready-made", que possui duas interferências, uma semântica e a outra sonora. Se movimentar a caixa, escuta-se um som que foi colocado dentro do novelo de cordel pelo amigo de Duchamp, Walter Arensberg, fazendo com que o que está dentro seja estranho a Duchamp e a todos nós. Talvez nunca se saiba o que está ali dentro, a não ser que se faça um raio $\mathrm{x}$ do objeto, mas isso retiraria o que há de intrigante nesse "ready-made" secreto.

Esse é apenas um dos "ready-made" que fazem pensar sobre a multiplicidade de labirintos contidos nos trabalhos de Duchamp. É na sua singularidade, um artista que se autodenomina "um protótipo". Essa sua afirmação demonstra como suas obras e a sua maneira de se relacionar com a vida gerou mais incógnitas do que respostas para quem se dispõe a tentar penetrar num universo multifacetado e cheio de ressonâncias que percorre a arte contemporânea.

No labirinto de espaços abertos pela tensão e extensão da linguagem de Duchamp, encontra-se Rrose Sélavy. 


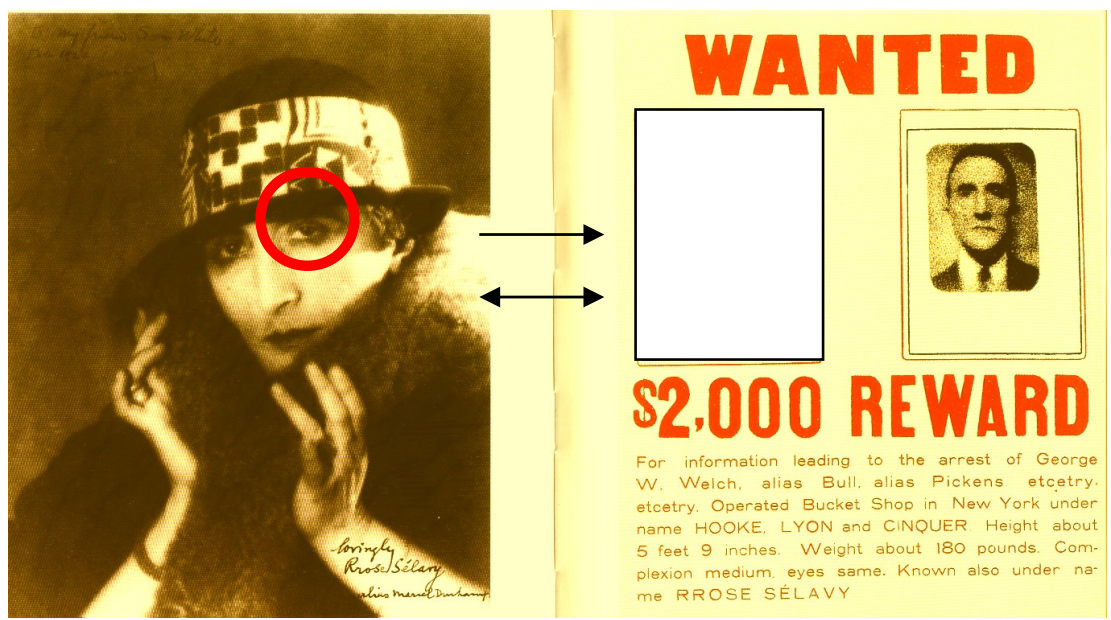

«Rrose Sélavy trouve qu'un incesticide doit coucher avec sa mère avant de la teur; lês punaises sont de rigueur.»

(Rrose Sélavy acha que um incesticida deve dormir com a mãe dele antes de a matar; os percevejos são exigidos) - (MINK, 1973, p. 126).

FIGURA 20 - Procura-se Joseph Beuys.

Flávia Dutra, 2004.

1.2 Entre vazios: o jogo de espelhos na labiríntica androgenia

Porque insistes, espelho permanente?

Porque duplicas, misterioso irmão,

O menor movimento desta mão?

Por que o teu reflexo de repente?

És o outro eu de que falou o grego

E espreitas desde sempre... (BORGES, 1998, p. 517).

Os períodos anteriores e posteriores à Primeira e à Segunda Guerra Mundial desencadearam fragmentações em todos os campos do saber e encontraram ressonâncias variadas, fazendo com que a história da arte passasse a ser percebida de forma labiríntica. Pode-se ressaltar a comparação feita por Bailly: 
A revolução formal da arte moderna pode ser comparada com a do quatroccento. Mesma explosão de nomes, de indivíduos, de liberdade, mesma aceleração das invenções de um espaço, de uma cena girante e lisa... Porque nada se repete, as comparações são possíveis: Marcel Duchamp mantém suas distâncias com seu século como Leonardo da Vinci o fez com o seu (BAILLY, 1984, p. 5-6).

Essas distâncias aproximam Duchamp de Leonardo da Vinci através da arte e da ambigüidade que ambos sugeriram a todos os viajantes do tempo, um questionamento atemporal-labirintíco que faz com que a história da arte seja revista através de um posicionamento crítico. Ambos os artistas são investigadores silenciosos que riram do mundo e propuseram uma discussão sobre a arte através da ironia e da provocação.

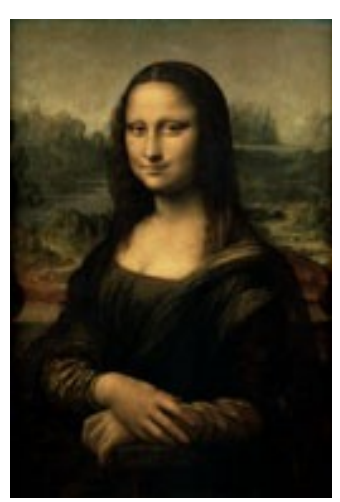

FIGURA 21 - Mona Lisa.

Leonardo da Vinci, c. 1503.

A enigmática "Mona Lisa" (Fig. 21) tornou-se fonte de estudos em diversas áreas, pois, se de um lado ela, Gioconda, sorri, do outro há uma indagação sobre quem está ali. Também a paisagem onde a "Mona Lisa" se encontra causa estranheza, pois a técnica do sfumatto faz com que os contornos se diluam na atmosfera e deixa transparecer uma espécie de visão aérea que conduz a pensar se existe aquele lugar. A forma de pensar labiríntica continua, pois, afinal, quem é quem?

A análise sobre a face de "Mona Lisa", feita por Dimitri Merejkowski em "The Romance of Leonardo da Vinci", escrito por volta de 1902, foi uma das primeiras a suscitar a possível relação que poderia haver entre Leonardo e Mona Lisa Gioconda como reflexo um do outro. Uma espécie de jogo de espelhos é proposta por Dimitri no romance: "E pareceu para Giovanni que agora Leonardo e Mona Lisa estavam como dois espelhos, os quais 
refletiam, eles mesmos, um no outro, onde a profundidade alcança a eternidade" (MEREJKOWSKI, 1928, p.510-11).

Em 1910, Freud focou sua análise na psicossexualidade de Leonardo da Vinci. Partindo de algumas de suas obras, principalmente a "Mona Lisa", essa passa a ser considerada como sendo o próprio retrato da projeção da sexualidade ambígua de Leonardo da Vinci. Provavelmente, Duchamp, que se interessava pelos estudos da mente e pelas descobertas de Freud, tenha colocado o bigode e a barba numa reprodução da "Mona Lisa" (FIG. 22) a partir desses relatos e de suas próprias convicções em relação à presença de uma certa androgenia labiríntica existente na obra e na própria vida

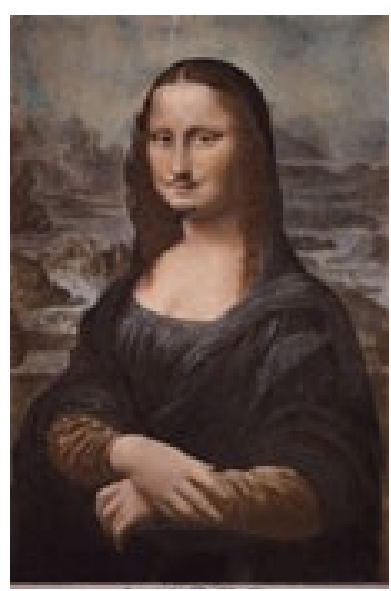

Figura22-L.H.O.O.

Marcel Duchamp, 1964, réplica do "ready-made" de 1919. de Leonardo da Vinci.

Ao enviar anteriormente, em 1917, um objeto masculino cujo titulo e a "ronte" (rIg. 23) para a exposição organizada pela "Society of Independent Artists" e, posteriormente, ao se apropriar da obra de outro artista fazendo uma interferência na mesma, Duchamp fez do jogo um labirinto colocando em xeque a questão da propriedade e da autenticidade. Essa atitude foi vista, na época, como uma provocação a toda a sacralização que existia em relação às obras e aos artistas. Isso abalou os parâmetros da arte moderna, tanto em relação aos artistas quanto à Instituição. Os primeiros foram deslocados de um lugar em que por muito tempo habitaram, pois já não detinham solitariamente a autonomia da obra.

Pode-se começar a pensar no artista mais como um propulsor de idéias e críticas da arte e essas dentro, fora e na periferia do próprio sistema labirintíco. Para Paulo Sérgio Duarte, "Duchamp é uma questão já incorporada/superada como a Geometria, aqui no 
Rio de Janeiro, para nossos melhores neoconcretos" (BUREN, 2001, p. 16), mas é necessário refletir se existe uma superação quando, no decorrer de seu discurso, comenta que "a discussão do sistema é feita de dentro, mas não por infiltração, pela subversão explícita e evidenciada de seus instrumentos" (BUREN, 2001, p. 16). O que Paulo Sérgio não abrange é que o próprio discurso de Duchamp traz uma ironia que subverte o sistema e a idéia. Não parece que Duchamp já tenha sido incorporado e principalmente superado, quando se pode ler, por exemplo, na Folha de São Paulo, um artigo sobre a 26a Bienal de São Paulo que traz o título: "É arte ou não é?" (BERGAMO, 2004). Essa pergunta, apesar dos anos, ainda ecoa, pois Duchamp deixou a abertura para a arte contemporânea e para uma espécie de sistema labirintíco que engendra os seus mecanismos, no qual "a concepção do sujeito mestre e proprietário de seus pensamentos" (RANCIÈRE, 2003) ainda está em suspenso.

Em relação aos sistemas instituídos pelos museus e galerias, os mesmos perderam, com a atitude de Duchamp, autonomia sobre as obras de arte, que passaram a ser usadas e reutilizadas por outros artistas. Isso foi um ponto de referência teórico e artístico que se estendeu até os artistas das décadas seguintes e hoje vários trabalhos, como os de Sophie Calle e Cyndy Sherman, são parte de uma reflexão sobre o uso da imagem e a questão da autoria, onde:

o que se perde então não é nem a personalidade do autor nem a materialidade da obra. É o trabalho pelo qual essa personalidade se alterava nessa materialidade. A retirada da obra em direção à idéia não anula a realidade material da obra. Mas ela tende a transformar a propriedade paradoxal da obra impessoal em propriedade lógica de uma patente de inventor. Nesse sentido o autor contemporâneo é mais estritamente proprietário do que jamais o foi qualquer autor (RANCIERE, 2003).

Ao se observarem as "réplicas" utilizadas por Duchamp, como a da "Fonte" de 1964 (Fig. 23), não se verão mudanças em relação ao conceito, pois o que importa é a mensagem, a idéia em si. Esse "ready-made", como vários outros que Duchamp reconstruiu, 
demonstra que a questão se encontra na mensagem: "outro aspecto do "ready-made" é que não tem nada de único... a réplica de um "ready-made" transmite a mesma mensagem; de resto, quase todos os "ready-mades" que hoje existem não são originais no sentido visual do termo" (DUCHAMP, 1978, p. 164).
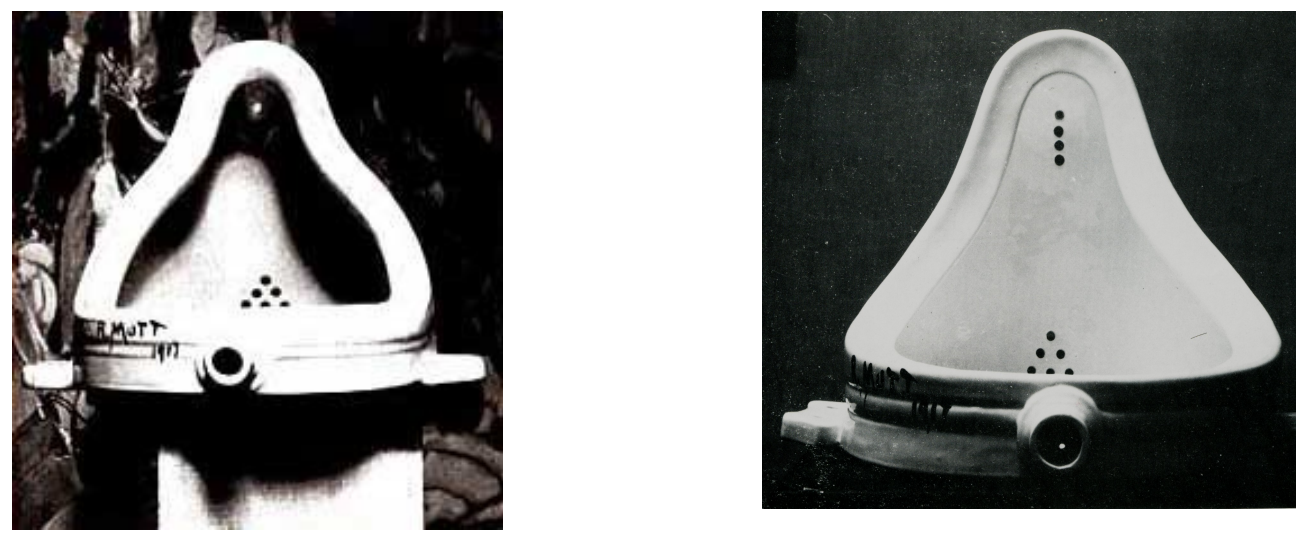

FIGURAS 23 e 24 - Fonte (A- 1917, B- 1964).

Marcel Duchamp

Existem outras questões que podem ser levantadas em relação à obra "L.H.O.O.Q". Esse "ready-made" foi feito a partir de um postal que continha uma reprodução da "Gioconda". Duchamp, além de colocar o bigode e a barba, que são, aparentemente, as principais interferências feitas, cria também um jogo de palavras no título "L.H.O.O.Q", que foneticamente em Francês significa "Elle a chaud au cul" (ela tem calor no rabo).

Em relação a esse "ready-made", as questões surgidas mantiveram-se quase sempre ligadas a esse enunciado, mas, hoje, com o uso de computadores, novas pesquisas têm surgido e ampliado as questões.

Para a artista Rhonda Roland Shearer, que tem pesquisado as obras de Duchamp utilizando novas mídias (Fig. 25), o "ready-made L.H.O.O.Q" de 1919 contém a face de Duchamp impressa e foi desenvolvido através de uma montagem feita a partir de uma litografia, onde Duchamp teria inserido seu retrato. Isso demonstra a importância dos 
"ready-mades aidé", que possuem interferências e participações diretas ou indiretas na sua realização da androgenia.

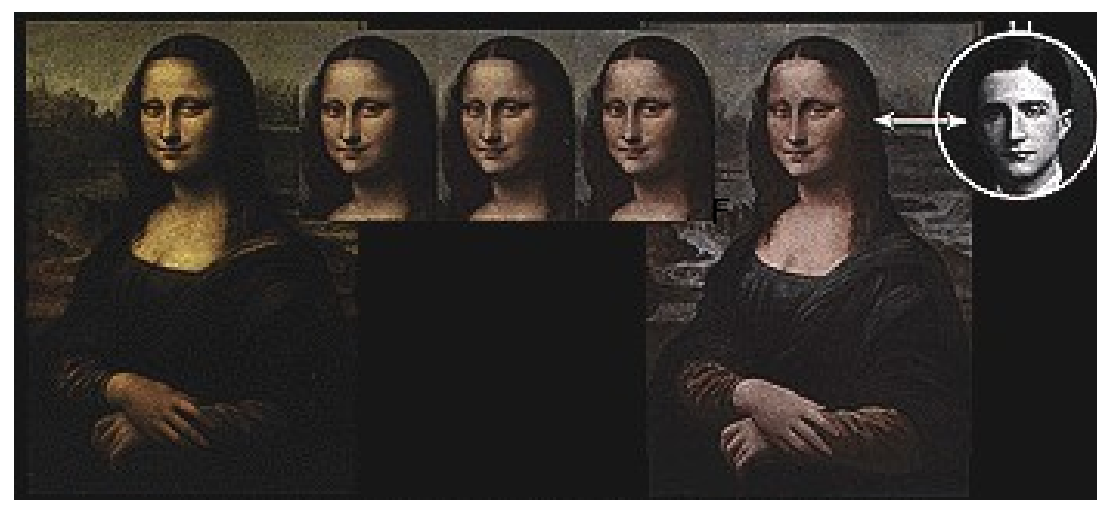

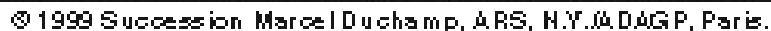

FIGURA 25 - Detalhe do estudo desenvolvido.

Shearer, 1999.

Existe um outro "L.H.O.O.Q", de 1919, que também é um "ready-made" ajudado, no qual há uma interferência feita a lápis. Pode-se observar melhor (Fig. 26) que o olho direito sofreu uma modificação. Não se sabe muito bem para onde se está olhando, tanto a figura como quem observa, pois o olho esquerdo parece apontar para a direita e o olho direito para frente. A outra "L.H.O.O.Q" (FIG. 27) foi desenvolvida como cartão de visita em 1965 e contém uma modificação no próprio título, que assume a ambigüidade tanto de Leonardo da Vinci quanto de Marcel Duchamp, ao chamar de "L.H.O.O.Q. Barbeada". Esse título reafirma o que já se vê e deixa o que está por trás dessa visualidade transparecer como uma espécie de trans-sexualidade que Duchamp apontou, por volta de 1920, ao personificar-se em Rrose Sélavy (FIG. 28) e ao utilizar esse heterônimo em várias obras, como uma espécie de um outro eu que se desloca num jogo de espelhos androgino-labirintico. 


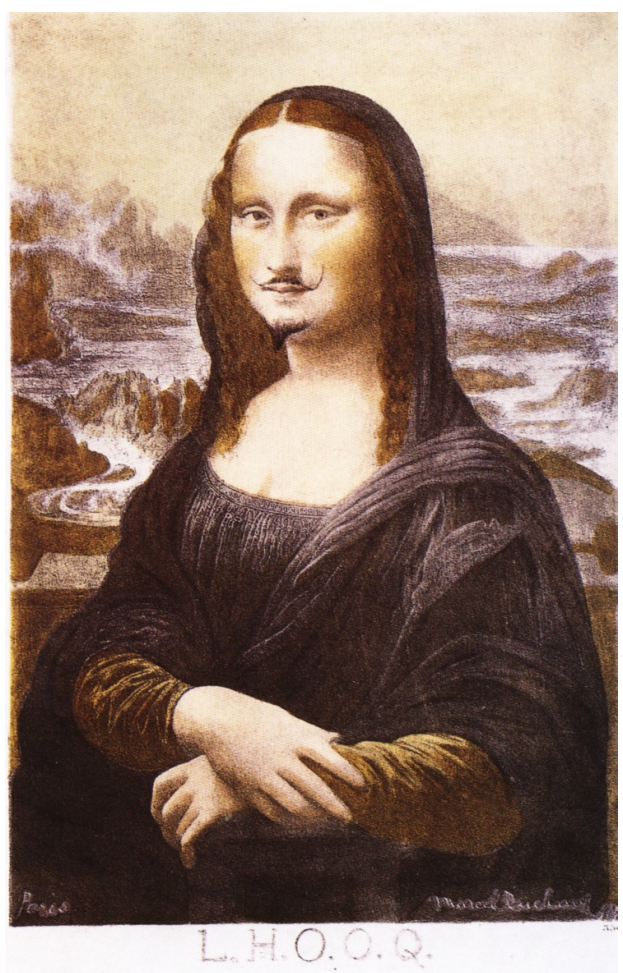

FIGURA 27 - L.H.O.O.Q. barbeada. Marcel Duchamp, 1965.

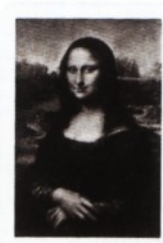

L.HOOQQ.
FIGURA 26 - L.H.O.O.Q.

Marcel Duchamp, 1919. 


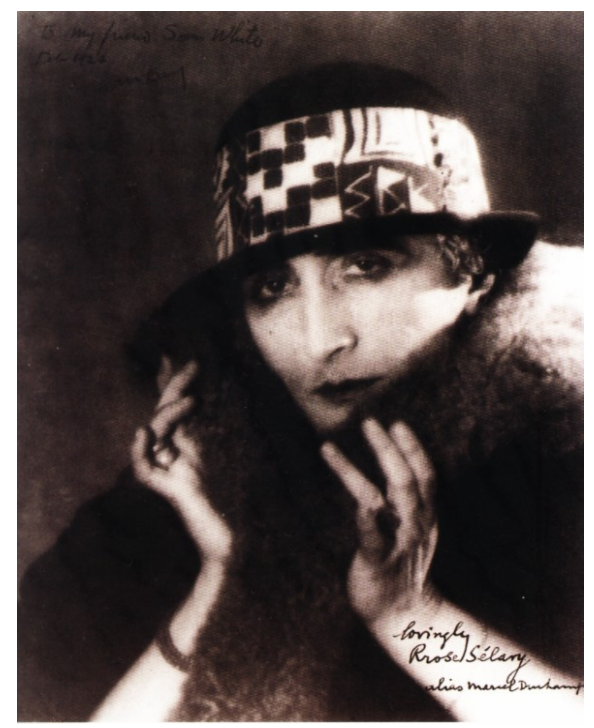

FIGURA 28 - Duchamp como Rrose Sélavy.

Man Ray, 1920.

- Desejava, com efeito, trocar de identidade e a primeira idéia que me veio foi a de adotar um nome judeu. Eu era católico e já seria uma mudança passar de uma religião a outra! Não encontrei um nome judeu que me agradasse ou que me tentasse e, de repente, tive uma idéia: por que não trocar de sexo? É muito mais simples! Então, daí veio o nome de Rrose Sélavy (DUCHAMP apud CABANNE, 2001, p. 110). 


\section{Referências}

BACHELARD, Gaston. La Poétique de I Éspace. Paris: Presses Universitaries de France, 1961, p.200-01.

BAILLY, Jean-Christophe. Marcel Duchamp. Paris: Fernand Hazan, 1984, p.5-6.

BERGAMO, Mônica. É arte ou não é?. FOLHA DE S.Paulo, caderno Ilustrada, domingo 17 de outubro de 2004.

BORGES, Jorge Luis. Obras completas. Vol2. Lisboa: Teorema, 1998. p.314,366,517.

BUREN, Daniel. Daniel Buren: textos e entrevistas escolhidos(1967-2000)/ organização Paulo Sergio Duarte [tradução, Ana Maria Castro Santos, André Sena, Lúcia Maia]- Rio de Janeiro: Centro de Arte Hélio Oiticica, 2001, p.16.

CABANNE, Pierre. Marcel Duchamp: engenheiro do tempo perdido. São Paulo: Perspectiva, 2001, p.24.

CALVINO, Ítalo. As cidades invisíveis. Tradução Diogo Mainardi. São Paulo: Companhia das Letras, 1990, p.67.

COSTA, Cláudio da. A arte moderna e contemporânea: a lógica da superfície em dois momentos. http:www.digitagrama.com.br . Acesso em 2005.

DA VINCI, Leonardo, apud CHEVALIER, Jean; GHEERBRANT, Alain. Dicionário dos símbolos. Rio de Janeiro: José Olímpio, 1982, p.530.

DELEUZE, Gilles; GuATTARI, Félix. Mil Platôs: Capitalismo e Esquizofrenia. Vol1. Tradução Aurélio Guerra Neto e Célia Pinto Costa. Fio de Janeiro: Ed.34, 1995, p.15.

DUCHAMP, Marcel. Escritos. Duchamp du signe. Barcelona: Gustavo Gili, p.42,164.

DUCHAMP apud CABANNE, Pierre. Marcel Duchamp: Engenheiro do tempo perdido. São Paulo: Ed.Perspectiva S.A., 2001, p.47,110. 
HABERMAS, Jurgen. Pensamento pós-metafísico: estudos filosóficos. Rio de Janeiro: Tempo Brasileiro, 1990. p.237.

HEARTNEY, Eleonor. Pós-Modernismo. São Paulo: Cosac \& Naify, 2002, p.9.

MATOS, Olgária F. http://www.patio.com.br/labirinto/paisagensurbanas.html.

MEREJKOWSKI, Dimitri. The romance of Leonardo da Vinci. Bernard Guilbert Guerney, tr.New York. The Modern Library, 1928, p.510-11.

RANCIÈRE, Jacques. Autor morto ou artista vivo demais? Folha de São Paulo, cadeno mais! São Paulo, 6 de abril de 2003.

VELLOSO, Rita de Cássia L. O Cotidiano Selvagem: a arquitetura na internacional "situtionniste". Entre riscos \& rabiscos. Publicação dos alunos da Faculdade de Arquitetura e Urbanismo Izabela Hendrix, set/out 2002, p.17.

VENEROSO, Maria do Carmo F. Caligrafias e escrituras: diálogo e intertexto no processo escritural nas artes do século XX. [Tese de Doutorado em Estudos Literários]. Belo Horizonte:Faculdade de Letras da UFMG, 2000, p.173.

WITTGENSTEIN, Ludwig. Investigações Filosóficas; Tradução Marcos G. Montagnoli. Rio de Janeiro: Vozes, 1994, p.244. 